\title{
Review \\ Clinical review: Primary influenza viral pneumonia
} Jordi Rello ${ }^{1}$ and Aurora Pop-Vicas ${ }^{2}$

\begin{abstract}
${ }^{1}$ Critical Care Department, Joan XXIII University Hospital, CIBERES Enfermedades Respiratorias, IISPV, Mallafre Guasch 4, 43007 Tarragona, Spain ${ }^{2}$ Division of Infectious Disease, Memorial Hospital of Rhode Island, 111 Brewster Street, Pawtucket, RI 02860, USA
\end{abstract}

Corresponding author: Aurora Pop-Vicas, Aurora_Pop-Vicas@brown.edu

Published: 21 December 2009

This article is online at http://ccforum.com/content/13/6/235

(c) 2009 BioMed Central Ltd

Critical Care 2009, 13:235 (doi:10.1186/cc8183)

\begin{abstract}
Primary influenza pneumonia has a high mortality rate during pandemics, not only in immunocompromised individuals and patients with underlying comorbid conditions, but also in young healthy adults. Clinicians should maintain a high index of suspicion for this diagnosis in patients presenting with influenza-like symptoms that progress quickly ( 2 to 5 days) to respiratory distress and extensive pulmonary involvement. The sensitivity of rapid diagnostic techniques in identifying infections with the pandemic $2009 \mathrm{H} 1 \mathrm{~N} 1 \mathrm{v}$ influenza strain is currently suboptimal. The most reliable real-time reverse transcriptase-polymerase chain reaction molecular testing is available in limited clinical settings. Despite 6 months of pandemic circulation, most novel H1N1v pandemic strains remain susceptible to oseltamivir. Ensuring an appropriate oxygenation and ventilation strategy, as well as prompt initiation of antiviral therapy, is essential in management.
\end{abstract}

\section{Introduction}

As the novel swine-origin influenza $A(H 1 N 1) v$ global pandemic is under way, the medical community has already experienced an increase in hospitalizations from influenzarelated complications in many geographic regions. Primary viral pneumonia is recognized as the most severe pulmonary manifestation of influenza. While uncommon during seasonal epidemics, the syndrome has been well documented during the H2N2 pandemic of 1957-1958 and is thought to be responsible for much of the mortality associated with the young healthy adult population during the $1918 \mathrm{H} 1 \mathrm{~N} 1$ pandemic [1]. This paper reviews the clinical aspects of influenza and primary influenza pneumonia that may be of most interest to the practicing physician in the 2009 pandemic environment.

\section{Epidemiology}

Seasonal influenza epidemics occur each year as a result of minor changes in the antigenic characteristics of the hemagglutinin and neuraminidase glycoproteins of the influenza viruses (antigenic drift) [2]. The morbidity and mortality associated with seasonal influenza outbreaks are significant, especially in older patients, who incur more than $90 \%$ of the influenza-related mortality each year [3]. Factors contributing to their increased vulnerability include a decline in cellmediated and humoral immune responses, a reduction in lung compliance and respiratory muscle strength, a diminished cough reflex associated with normal aging, the frequent presence of multiple comorbid conditions, nutritional deficiencies, and in the case of residents of long-term care facilities, greater exposure risk due to close living quarters and shared caregivers $[4,5]$.

Influenza pandemics occur less frequently, as a result of major changes in the surface glycoproteins of the virus (antigenic shift). The emerging novel influenza strain then easily spreads into an immunologically susceptible population. Consequently, pandemics are characterized by a shift in mortality toward the otherwise young and healthy 18to 35-year-old adults, with relative sparing of older patients, as evidenced by epidemiological analyses of the 1918 influenza A pandemic [6]. This is likely due to the persistence of immunological memory in older patients after previous exposures to $\mathrm{H} 1$-type viruses similar to the pandemic strain $[7,8]$. The virulence of the pandemic strain may also play a role, as demonstrated by recent experiments with the highly fatal 1918 influenza strain [9].

Preliminary data from the $2009 \mathrm{H} 1 \mathrm{~N} 1$ pandemic suggest a similar shift in age-related mortality. An analysis of 532 cases of 2009 pandemic H1N1 influenza $A$ in the US, for example, has revealed that $60 \%$ of the cases occurred in patients not older than 18 years of age and that only $5 \%$ occurred in patients older than 50 years [10]. In the cohorts recently tested, the modest extent of immunological memory in older patients was confirmed by the presence of serum crossreactive antibodies to the pandemic $\mathrm{H} 1 \mathrm{~N} 1$ influenza $A$ strain found in $33 \%$ of the adults older than 60 years of age versus $6 \%$ to $9 \%$ of the adults 18 to 64 years of age and none of the children [11]. 
Influenza attack rates during seasonal epidemics vary between $10 \%$ and $20 \%$ but can be much higher during pandemics. For example, an analysis of the pandemic 2009 H1N1 influenza A outbreak in La Gloria, Veracruz, found clinical attack rates of $29 \%$ in adults older than 15 years and $61 \%$ in children younger than 15 years of age [12]. However, these rates may be different in geographic areas of low population density.

Groups at high risk for severe disease and complications secondary to 2009 pandemic H1N1 influenza A include patients with underlying pulmonary (asthma) and cardiac comorbid conditions, some immunosuppressive states, pregnancy and post-partum states, diabetes mellitus, obesity [13,14], and, in children, prior neurological disabilities [15]. Severe primary $\mathrm{H} 1 \mathrm{~N} 1$ influenza pneumonia can also affect young adults without any underlying comorbidities [14].

\section{Transmission and infectiousness}

Person-to-person transmission occurs primarily through droplet spread via small particle-sized aerosols generated by coughing, sneezing, or talking [16]. Airborne transmission should be considered in those patients exposed to aerosolgenerating techniques, such as intubation or mechanical ventilation.

The incubation period is usually 24 to 48 hours. In the absence of antiviral treatment, viral shedding starts within 24 hours before the onset of symptoms and continues for approximately 5 days in healthy adults [17]. Viral shedding can last longer in children, patients with extensive comorbidities, older patients, patients who undergo mechanical ventilation, and immunocompromised hosts [18-20]. The infectious period can be significantly reduced by the use of antiviral medications within the first 48 to 96 hours of illness [20].

\section{Pathogenesis}

After inhalation, the virus is deposited onto the respiratory tract epithelium, where it attaches to ciliated columnar epithelial cells via its surface hemagglutinin. Local host defenses, such as mucociliary clearance, or secretion of specific secretory $\lg A$ antibodies can remove some of the virus particles. However, if mucociliary clearance is impaired (as in smokers [21] or older patients [22]) or secretory antiinfluenza $\lg \mathrm{A}$ antibodies are absent (as in no antecedent exposure to the virus), infection continues unabated [23]. Respiratory epithelial cells are invaded, and viral replication occurs. Newer viruses then infect larger numbers of epithelial cells, shut off the synthesis of critical proteins, and ultimately lead to host cell death [24].

In patients with uncomplicated influenza, bronchoscopy typically reveals diffuse inflammation and edema of the larynx, trachea, and bronchi, and biopsy may show cellular infiltration with lymphocytes and histocytes and desquamation of the ciliated columnar epithelium [25]. In patients with severe influenza infections that progress to primary viral pneumonia, the involvement of the respiratory tree is extensive, with necrotizing tracheobronchitis, ulceration and sloughing of the bronchial mucosa [26], hyperemic alveolar capillaries with intra-alveolar hemorrhage, infiltration of alveolar spaces with fluid, fibrin, and cellular exudates, and lining of the alveoli with acellular hyaline membranes [1]. Autopsies from patients with primary influenza pneumonia confirmed bilateral severe hemorrhagic pneumonitis with interstitial inflammation, diffuse alveolar damage, and heavy viral loads observed in the periphery of the lungs.

\section{Clinical manifestations}

The clinical features of uncomplicated influenza are virtually indistinguishable from those of other respiratory viral infections. Influenza is classically characterized by an abrupt onset of headache, high-grade fever, chills, dry cough, pharyngeal irritation, myalgias, malaise, and anorexia. The fever lasts an average of 3 days (range of 2 to 8 days). The cough, initially nonproductive and nonpurulent, may persist for weeks. Bronchial hyper-reactivity and small-airway dysfunction are often present in influenza virus infection. In the presence of asthma or structural lung disease, wheezing may be a prominent manifestation [24]. Vomiting and diarrhea, while rare in seasonal influenza, have been frequently reported in infections with the 2009 pandemic influenza A H1N1v strain [10], particularly in children.

The clinical presentation of influenza in the immunocompromised host may be more subtle and manifest only as coryza; similarly, the classic fever symptom may be absent in the older patient, who may present only with lethargy, confusion, anorexia, and cough [27]. Influenza pneumonia and respiratory complications in patients with Th1 defects, such as HIV infection, are uncommon.

Pneumonia and the acute respiratory distress syndrome (ARDS) account for the majority of severe morbidity and mortality that accompany pandemic influenza infection [14]. Pneumonia may occur as a continuum of the acute influenza syndrome when caused by the virus alone (primary pneumonia) or as a mixed viral and bacterial infection after a delay of a few days (secondary pneumonia) [28]. Identifying patients who are more likely to develop severe complications from influenza pneumonia requires a high clinical vigilance. Commonly used pneumonia severity assessment tools, such as the Pneumonia Severity Index [29] or CURB65 [30], are not useful in deciding which patients to hospitalize in the context of primary influenza pneumonia since these tools have not been developed and validated during a pandemic scenario. Thus, careful triage in the emergency department and early identification of young patients with decreased oxygen saturation, respiratory rate above 25 , concomitant diarrhea, or hypotension are crucial. Elevated lactate dehydrogenase, creatine phosphokinase, and creatinine at hospital admission may also serve as prognostic indicators of 


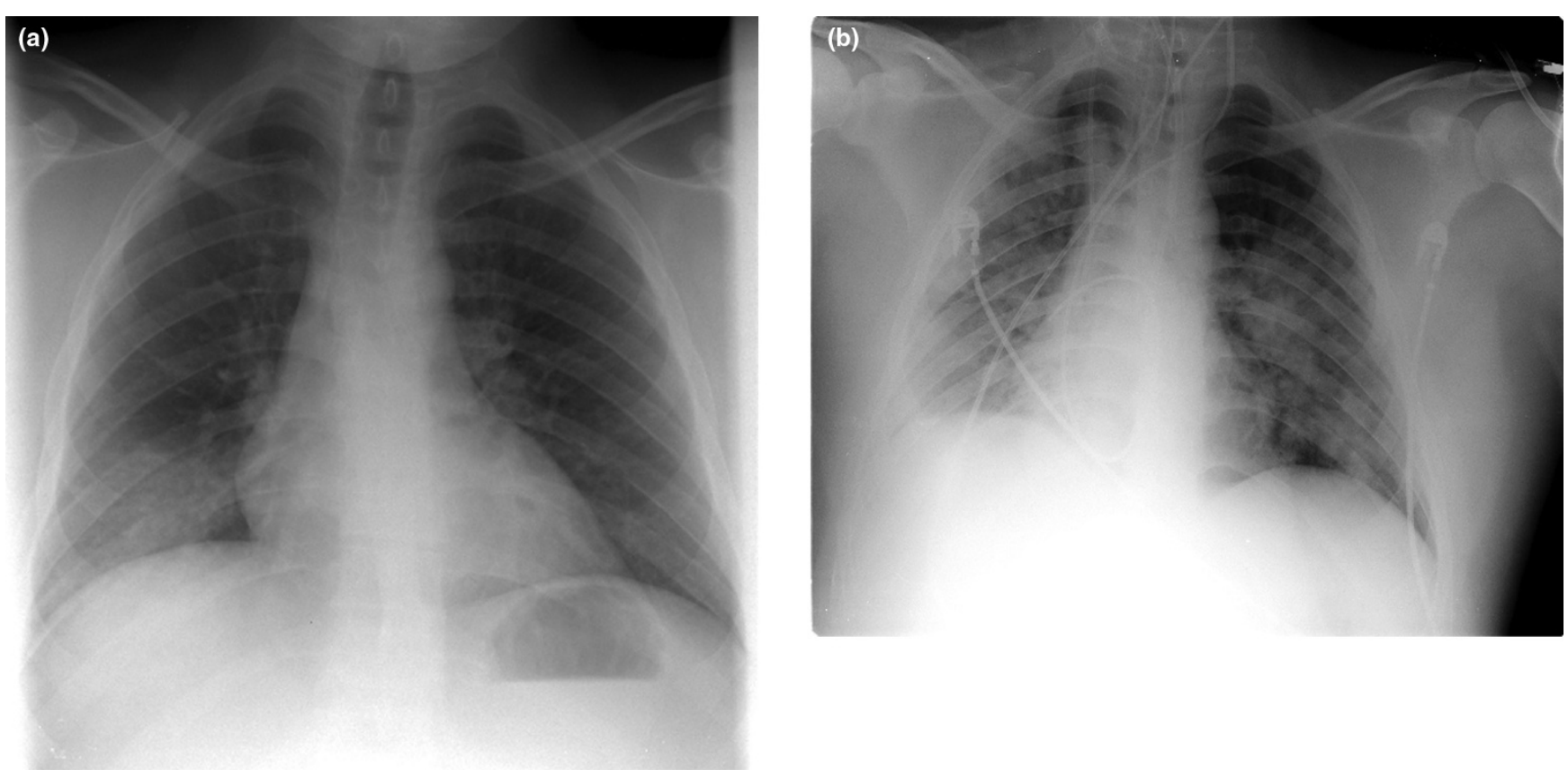

Chest x-rays of a patient with primary H1N1 (swine-origin influenza A) influenza pneumonia on day 1 (a) and day 6 (b) of hospitalization.

severe disease [14]. C-reactive protein and procalcitonin are increased during this acute lung injury stage of early fibroproliferation.

The most ominous cases are those infections that progress rapidly to ARDS and multilobar alveolar opacification. These patients usually present with gradually increasing dyspnea and severe hypoxemia after an antecedent of 2 to 5 days of typical influenza symptoms [14]. The cough is usually productive of thin, often bloody, sputum with few cells. Hypoxemia increases progressively to the point of respiratory failure requiring intubation and mechanical ventilation, often after only one day of hospitalization [14].

The radiological appearance of primary influenza pneumonia can be difficult to distinguish on chest $x$-ray from pulmonary edema, given the presence of perihiliar congestion and hazy opacification, at least in the lower lobes (Figure 1a,b). Pleural effusions may also be present. Computed tomography scans (Figure 2) can add further diagnostic insight and may be useful to differentiate primary viral pneumonia from bronchiolitis and interstitial pneumonias, which occur frequently in children and young adults but have a benign outcome. Concomitant myopericarditis should be excluded by echocardiography. Concurrent pulmonary emboli, as suggested by early case reports from hospitalized patients with pandemic influenza A H1N1v 2009 in the US [13], may further contribute to clinical deterioration in some patients. However, the occurrence of concomitant pulmonary emboli has not been reproduced in other geographic regions so far.
Bacterial co-infection, though uncommonly reported in the early stages of the $2009 \mathrm{H} 1 \mathrm{~N} 1$ pandemic, may be more prevalent than initially thought. A recent analysis of lung specimens from 77 fatal cases of pandemic H1N1v 2009 infection found a prevalence of concurrent bacterial pneumonia in $29 \%$ of these patients [31]. The most common coinfecting bacterial pathogens were pneumococcus, Staphylococcus aureus, and Streptococcus pyogenes, with a median duration of illness of 6 days [31].

\section{Laboratory diagnosis}

The real-time reverse transcriptase-polymerase chain reaction (rRT-PCR) Swine Flu Panel for detection of pandemic H1N1 influenza, developed by the Centers for Disease Control and Prevention (Atlanta, GA, USA) and distributed to many laboratories in US and worldwide, is a reliable and timely method of diagnosing the pandemic strain [32,33]. The viral culture, while the gold standard in influenza diagnostics, takes several days before the results are known [24]. The direct fluorescent antigen influenza test was recently reported to have a sensitivity of $93 \%$ compared with the rRT-PCR [34], but the test requires considerable technical expertise in addition to a fluorescent microscope. The commonly used point-of-care rapid influenza tests provide results in less than 1 hour but are of only modest sensitivity for seasonal influenza viruses (63\%) [35] and unacceptably insensitive for the detection of pandemic $\mathrm{H} 1 \mathrm{~N} 1$ influenza $[35,36]$. Thus, for the majority of clinicians practicing during the 2009-2010 influenza pandemic, the access to a reliable and timely diagnostic modality may still be limited. As such, it is 
Figure 2

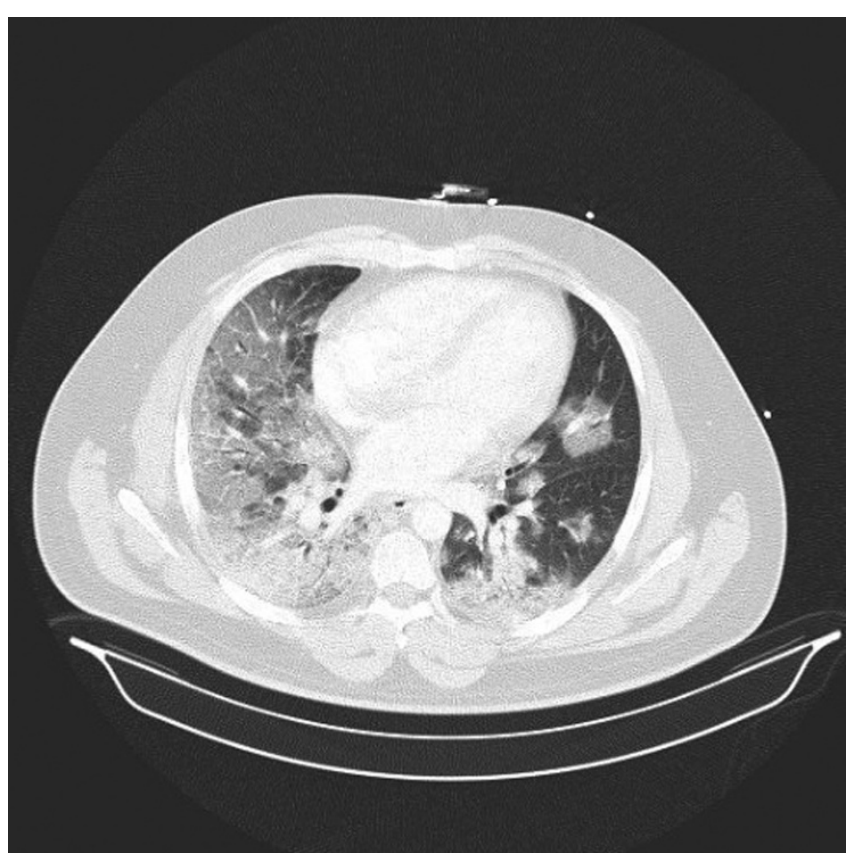

Computed tomography scan of the patient with primary H1N1 (swineorigin influenza A) influenza pneumonia whose chest $x$-rays appear in Figure 1.

reassuring to know that the patients presenting during influenza epidemics with both cough and fever within the first 48 hours of symptom onset are very likely to have actual influenza (79\% positive predictive value) [37].

\section{Management}

The majority of patients with primary influenza pneumonia require ventilatory support. Mortality is high but can be decreased with an optimal protective ventilatory strategy (tidal volume of not more than $6 \mathrm{~mL}$ per kilogram of predicted body weight, with a plateau airway pressure goal of not more than $30 \mathrm{~cm} \mathrm{H}_{2} \mathrm{O}$ ), as shown in Acute Respiratory Distress Syndrome Network clinical trials; this strategy is therefore recommended in acute lung injury $[38,39]$. Maintaining an adequate fluid balance is also important for survival in acute lung injury. The hemodynamic status should be optimized by appropriate repletion of intravascular volume deficits during the early systemic inflammatory stage [40]. Once acute lung injury has become established, a conservative fluid management protocol, which was associated with beneficial effects in clinical trials, should be considered [41,42]. In severe refractory cases of primary influenza pneumonia, some patients require venovenous extracorporeal membrane oxygenation support and continuous renal replacement for acute renal failure.

Antiviral treatment should be initiated as soon as possible, particularly in patients at high risk of complications. The majority of treatment benefits are derived when antivirals are initiated within the first 48 hours from onset of symptoms. Unfortunately, most patients with primary viral pneumonia receive oseltamivir after 3 to 8 days of influenza onset [14]. However, the experience with seasonal influenza suggests that a reduction in mortality for hospitalized patients has been documented even when oseltamivir was initiated after the first 48 hours following illness onset [43]. Thus, being out of the ideal therapeutic window should not be a reason to withhold antiviral treatment at any stage of active disease.

Both neuraminidase inhibitors (oseltamivir and zanamivir) are active against the novel H1N1v 2009 pandemic influenza A strain. The recommended adult dose for oseltamivir, considered the first-line therapy for $\mathrm{H} 1 \mathrm{~N} 1$ influenza infection, is $75 \mathrm{mg}$ orally twice a day for a total of 5 days [44]. Dose adjustment may be required in the presence of reduced creatinine clearance, but the dosage should be maintained for patients undergoing continuous venovenous hemodialysis. A recent World Health Organization treatment guideline for pharmacological management of 2009 pandemic H1N1v influenza A recommends the consideration of higher doses of oseltamivir (150 mg twice a day) and longer duration of treatment for patients with severe influenza pneumonia or clinical deterioration [44]. Since hospitalized patients can shed influenza virus for prolonged periods of time, extending antiviral treatment beyond the first 5 days of treatment in cases of persistent influenza symptoms may be necessary. However, clear guidelines for these circumstances have not been established, and clinical trials examining the appropriate treatment dose and duration for severe $\mathrm{H} 1 \mathrm{~N} 1$ influenza in various patient populations are acutely needed.

Development of oseltamivir resistance in novel $\mathrm{H} 1 \mathrm{~N} 1$ influenza, though still exceedingly rare, has been reported from several countries [45]. It should be suspected in patients who remain symptomatic or have evidence of viral shedding despite a full treatment course of oseltamivir. Immunosuppression and prior exposure to oseltamivir, such as receipt of prolonged post-exposure prophylaxis, increase the risk for oseltamivir resistance [45]. Zanamivir remains an effective therapeutic option for these cases. Zanamavir is also indicated in the rare circumstance when an oral route for oseltamivir administration is not available for critically ill patients in the intensive care unit. The risk of bronchospam rarely associated with zanamivir, particularly in patients with underlying reactive airway disease, can be minimized by concurrent bronchodilator administration.

Adamantanes (amantadine and rimantadine) have no activity against the 2009 influenza A H1N1v pandemic strain. They are effective for seasonal $\mathrm{H} 1 \mathrm{~N} 1$ influenza strains, which are $100 \%$ resistant to oseltamivir. Therefore, for patients presenting with primary influenza pneumonia in geographic regions where seasonal $\mathrm{H} 1 \mathrm{~N} 1$ strains are circulating in addition to the novel $\mathrm{H} 1 \mathrm{~N} 1$ pandemic strain, amantadine or 
rimantadine should be added to oseltamivir [46]. Rimantadine is also associated with immunomodulatory effects.

Patients presenting with severe influenza pneumonia who may have concurrent bacterial superinfection should also receive antibacterial agents effective against the most common etiologic pathogens, such as Streptococcus pneumoniae, Streptococcus pyogenes, and Staphylococcus aureus, including methicillin-resistant Staphylococcus aureus, according to published guidelines in the management of communityacquired pneumonia [47].

Corticosteroids remain controversial in persistent ARDS and are not routinely recommended [48]. Further research is required to clarify their impact on outcome. Whether other adjunctive immunomodulatory therapies such as statins, chloroquine, and fibrates could prove useful in the context of an influenza pandemic [49] remains to be determined.

\section{Conclusions}

Primary influenza pneumonia caused by the 2009 pandemic influenza A H1N1v strain, though rare, carries a high mortality. The rapid progression from initial typical influenza symptoms to extensive pulmonary involvement, with acute lung injury, can occur both in patients with underlying respiratory or cardiac morbidities and in young healthy adults, especially if obese or pregnant. Prompt initiation of effective antiviral treatment, appropriate oxygenation and ventilation support, and antibacterial treatment in the case of concurrent bacterial pneumonia are critical for survival. The most reliable and timely diagnostic method for 2009 pandemic influenza A $\mathrm{H} 1 \mathrm{~N} 1 \mathrm{v}$ infection is the rRT-PCR developed by the Centers for Disease Control and Prevention. Common 'point-of-care' rapid influenza tests are very insensitive. A negative test result in a patient with clinical symptoms compatible with influenza pneumonia does not accurately rule out influenza and should not be a deterrent to prompt oseltamivir treatment during this current pandemic. Further research is needed in order to identify the immunological dysfunction and determine the most effective dose and duration of oseltamivir as well as the role of potential adjunctive agents in the treatment of primary influenza pneumonia.

\section{Competing interests}

The authors declare that they have no competing interests.

This article is part of a review series on Influenza, edited by Steven Opal.

Other articles in the series can be found online at http://ccforum.com/series/influenza

\section{Acknowledgments}

The patient whose radiological images appear in Figures 1 and 2 has given written consent for their publication.

\section{References}

1. Louria DB, Blumenfeld HL, Ellis JT, Kilbourne ED, Rogers DE: Studies on influenza in the pandemic of 1957-1958. II. Pulmonary complications of influenza. J Clin Invest 1959, 38(1 Part 2):213-265.

2. Lai CJ, Markoff LJ, Sveda MM, Lamb RA, Dhar R, Chanock RM: Genetic variation of influenza $A$ viruses as studied by recombinant DNA techniques. Ann N Y Acad Sci 1980, 354:162-171.

3. Thompson WW, Shay DK, Weintraub E, Brammer L, Cox N, Anderson LJ, Fukuda K: Mortality associated with influenza and respiratory syncytial virus in the United States. JAMA 2003 , 289:179-186.

4. Opal SM, Girard TD, Ely EW: The immunopathogenesis of sepsis in elderly patients. Clin Infect Dis 2005, 41 Suppl 7: S504-512.

5. Falsey AR, Walsh EE: Viral pneumonia in older adults. Clin Infect Dis 2006, 42:518-524.

6. Simonsen L, Clarke MJ, Schonberger LB, Arden NH, Cox NJ, Fukuda K: Pandemic versus epidemic influenza mortality: a pattern of changing age distribution. J Infect Dis 1998, 178:5360.

7. Luk J, Gross P, Thompson WW: Observations on mortality during the 1918 influenza pandemic. Clin Infect Dis 2001, 33:1375-1378.

8. Ahmed R, Oldstone MB, Palese P: Protective immunity and susceptibility to infectious diseases: lessons from the 1918 influenza pandemic. Nat Immuno/ 2007, 8:1188-1193.

9. Kobasa D, Takada A, Shinya K, Hatta M, Halfmann P, Theriault S, Suzuki H, Nishimura H, Mitamura K, Sugaya N, Usui T, Murata T, Maeda Y, Watanabe S, Suresh M, Suzuki T, Suzuki Y, Feldmann $\mathrm{H}$, Kawaoka $\mathrm{Y}$ : Enhanced virulence of influenza $A$ viruses with the haemagglutinin of the 1918 pandemic virus. Nature 2004 431:703-707.

10. Novel Swine-Origin Influenza $A(H 1 N 1)$ Virus Investigation Team, Dawood FS, Jain S, Finelli L, Shaw MW, Lindstrom S, Garten RJ, Gubareva LV, Xu X, Bridges CB, Uyeki TM: Emergence of a novel swine-origin influenza $\mathrm{A}(\mathrm{H} 1 \mathrm{~N} 1)$ virus in humans. $N$ Engl J Med 2009, 360:2605-2615.

11. Serum cross-reactive antibody response to a novel influenza A (H1N1) virus after vaccination with seasonal influenza vaccine. MMWR Morb Mortal Wkly Rep 2009, 58:521-524.

12. Fraser C, Donnelly CA, Cauchemez S, Hanage WP, Van Kerkhove MD, Hollingsworth TD, Griffin J, Baggaley RF, Jenkins HE, Lyons EJ, Jombart T, Hinsley WR, Grassly NC, Balloux F, Ghani AC, Ferguson NM, Rambaut A, Pybus OG, Lopez-Gatell H, AlpucheAranda CM, Chapela IB, Zavala EP, Guevara DM, Checchi F, Garcia E, Hugonnet S, Roth C; WHO Rapid Pandemic Assessment Collaboration: Pandemic potential of a strain of influenza A (H1N1): early findings. Science 2009, 324:1557-1561.

13. Hospitalized patients with novel influenza $A$ (H1N1) virus infection - California, April-May, 2009. MMWR Morb Mortal Wkly Rep 2009, 58:536-541

14. Rello J, Rodríguez A, Ibañez P, Socias L, Cebrian J, Marques A, Guerrero J, Ruiz-Santana S, Marquez E, Del Nogal-Saez F, Alvarez-Lerma F, Martínez S, Ferrer M, Avellanas M, Granada R, Maraví-Poma E, Albert P, Sierra R, Vidaur L, Ortiz P, Prieto del Portillo I, Galván B, León-Gil C; H1N1 SEMICYUC Working Group: Intensive care adult patients with severe respiratory failure caused by Influenza A (H1N1)v in Spain. Crit Care 2009, 13:R148.

15. Lister P, Reynolds F, Parslow R, Chan A, Cooper M, Plunkett A, Riphagen $S$, Peters $M$ : Swine-origin influenza virus $H 1 N 1$, seasonal influenza virus, and critical illness in children. Lancet 2009, 374:605-607.

16. Advisory Committee on Immunization Practices, Smith NM, Bresee JS, Shay DK, Uyeki TM, Cox NJ, Strikas RA: Prevention and Control of Influenza: recommendations of the Advisory Committee on Immunization Practices (ACIP). MMWR Recomm Rep 2006, 55:1-42.

17. Carrat F, Vergu E, Ferguson NM, Lemaitre M, Cauchemez S, Leach $S$, Valleron AJ: Time lines of infection and disease in human influenza: a review of volunteer challenge studies. $A m$ $J$ Epidemiol 2008, 167:775-785. 
18. Leekha S, Zitterkopf NL, Espy MJ, Smith TF, Thompson RL, Sampathkumar $P$ : Duration of influenza A virus shedding in hospitalized patients and implications for infection control. Infect Control Hosp Epidemio/ 2007, 28:1071-1076.

19. Klimov Al, Rocha E, Hayden FG, Shult PA, Roumillat LF, Cox NJ: Prolonged shedding of amantadine-resistant influenzae $A$ viruses by immunodeficient patients: detection by polymerase chain reaction-restriction analysis. J Infect Dis 1995, 172: $1352-1355$.

20. Lee N, Chan PK, Hui DS, Rainer TH, Wong E, Choi KW, Lui GC, Wong BC, Wong RY, Lam WY, Chu IM, Lai RW, Cockram CS, Sung JJ: Viral loads and duration of viral shedding in adult patients hospitalized with influenza. J Infect Dis 2009, 200: 492-500.

21. Dye JA, Adler KB: Effects of cigarette smoke on epithelial cells of the respiratory tract. Thorax 1994, 49:825-834.

22. Puchelle $E$, Zahm JM, Bertrand A: Influence of age on bronchial mucociliary transport. Scand J Respir Dis 1979, 60:307-313.

23. Bender BS, Small PA Jr.: Influenza: pathogenesis and host defense. Semin Respir Infect 1992, 7:38-45.

24. Treanor JJ: Influenza virus. In Principles and Practice of Infectious Disease. Vol. 2. Edited by Mandell G, Bennett JE, Dolin R. Philadelphia, PA: Churchill Livingstone; 2005:2060.

25. Walsh JJ, Dietlein LF, Low FN, Burch GE, Mogabgab WJ: Bronchotracheal response in human influenza. Type A, Asian strain, as studied by light and electron microscopic examination of bronchoscopic biopsies. Arch Intern Med 1961, 108: 376-388.

26. Oseasohn R, Adelson L, Kaji M: Clinicopathologic study of thirty-three fatal cases of Asian influenza. N Engl J Med 1959, 260:509-518.

27. Walsh EE, Cox C, Falsey AR: Clinical features of influenza A virus infection in older hospitalized persons. J Am Geriatr Soc 2002, 50:1498-1503.

28. Rothberg MB, Haessler SD, Brown RB: Complications of viral influenza. Am J Med 2008, 121:258-264.

29. Fine MJ, Auble TE, Yealy DM, Hanusa BH, Weissfeld LA, Singer $\mathrm{DE}$, Coley CM, Marrie TJ, Kapoor WN: A prediction rule to identify low-risk patients with community-acquired pneumonia. $N$ Engl J Med 1997, 336:243-250.

30. Lim WS, van der Eerden MM, Laing R, Boersma WG, Karalus N, Town GI, Lewis SA, Macfarlane JT: Defining community acquired pneumonia severity on presentation to hospital: an international derivation and validation study. Thorax 2003, 58: 377-382.

31. Bacterial coinfections in lung tissue specimens from fatal cases of 2009 pandemic influenza A (H1N1) - United States, May-August 2009. MMWR Morb Mortal Wkly Rep 2009, 58: 1071-1074.

32. US Centers for Disease Control and Prevention: Interim guidance on specimen collection, processing, and testing for patients with suspected swine-origin influenza $A(H 1 N 1)$ virus infection [http://www.cdc.gov/h1n1flu/specimencollection.htm].

33. World Health Organization: The Weekly Epidemiological Record (WER) [http://www.who.int/wer].

34. Pollock NR, Duong S, Cheng A, Han LL, Smole S, Kirby JE: Ruling out novel H1N1 influenza virus infection with direct fluorescent antigen testing. Clin Infect Dis 2009, 49:e66-68.

35. Faix DJ, Sherman SS, Waterman SH: Rapid-test sensitivity for novel swine-origin influenza $\mathrm{A}(\mathrm{H} 1 \mathrm{N1})$ virus in humans. $N$ Engl J Med 2009, 361:728-729.

36. Evaluation of rapid influenza diagnostic tests for detection of novel influenza A (H1N1) Virus - United States, 2009. MMWR Morb Mortal Wkly Rep 2009, 58:826-829.

37. Monto AS, Gravenstein S, Elliott M, Colopy M, Schweinle J: Clinical signs and symptoms predicting influenza infection. Arch Intern Med 2000, 160:3243-3247.

38. Dellinger RP, Carlet JM, Masur H, Gerlach H, Calandra T, Cohen J, Gea-Banacloche J, Keh D, Marshall JC, Parker MM, Ramsay G, Zimmerman JL, Vincent JL, Levy MM; Surviving Sepsis Campaign Management Guidelines Committee: Surviving Sepsis Campaign guidelines for management of severe sepsis and septic shock. Crit Care Med 2004, 32:858-873.

39. Ventilation with lower tidal volumes as compared with traditional tidal volumes for acute lung injury and the acute respiratory distress syndrome. The Acute Respiratory Distress Syndrome Network. N Engl J Med 2000, 342:1301-1308.
40. Hollenberg SM, Ahrens TS, Annane D, Astiz ME, Chalfin DB Dasta JF, Heard SO, Martin C, Napolitano LM, Susla GM, Totaro R, Vincent JL, Zanotti-Cavazzoni S: Practice parameters for hemodynamic support of sepsis in adult patients: 2004 update. Crit Care Med 2004, 32:1928-1948.

41. National Heart, Lung, and Blood Institute Acute Respiratory Distress Syndrome (ARDS) Clinical Trials Network, Wiedemann HP Wheeler AP, Bernard GR, Thompson BT, Hayden D, deBoisblanc $\mathrm{B}$, Connors AF Jr., Hite RD, Harabin AL: Comparison of two fluid-management strategies in acute lung injury. $N$ Engl J Med 2006, 354:2564-2575.

42. Rivers EP: Fluid-management strategies in acute lung injuryliberal, conservative, or both? N Engl J Med 2006, 354:25982600.

43. Ison MG: Influenza in hospitalized adults: gaining insight into a significant problem. J Infect Dis 2009, 200:485-488.

44. World Health Organization: WHO Guidelines for Pharmacological Management of Pandemic (H1N1) 2009 Influenza and other Influenza Viruses. Publication date: 20 August 2009 [http://www.who.int/csr/resources/publications/swineflu/h1n1_us e_antivirals_20090820/en/].

45. World Health Organization: Antiviral use and the risk of drug resistance Pandemic (H1N1) 2009 briefing note 12; 25 September 2009 [http://www.who.int/csr/disease/swineflu/notes/ h1n1 antiviral use 20090925/en/].

46. Fiore AE, Shay DK, Broder K, Iskander JK, Uyeki TM, Mootrey G, Bresee JS, Cox NS; Centers for Disease Control and Prevention (CDC); Advisory Committee on Immunization Practices (ACIP): Prevention and control of influenza: recommendations of the Advisory Committee on Immunization Practices (ACIP), 2008. MMWR Recomm Rep 2008, 57:1-60.

47. Mandell LA, Bartlett JG, Dowell SF, File TM Jr., Musher DM, Whitney C; Infectious Diseases Society of America: Update of practice guidelines for the management of communityacquired pneumonia in immunocompetent adults. Clin Infect Dis 2003, 37:1405-1433.

48. Steinberg KP, Hudson LD, Goodman RB, Hough CL, Lanken PN, Hyzy R, Thompson BT, Ancukiewicz M; National Heart, Lung, and Blood Institute Acute Respiratory Distress Syndrome (ARDS) Clinical Trials Network: Efficacy and safety of corticosteroids for persistent acute respiratory distress syndrome. $N$ Engl $J$ Med 2006, 354:1671-1684.

49. Fedson DS: Confronting an influenza pandemic with inexpensive generic agents: can it be done? Lancet Infect Dis 2008 , 8:571-576. 